Max-Planck-Institut für demografische Forschung

Max Planck Institute for Demographic Research

Konrad-Zuse-Strasse 1 - D-18057 Rostock · GERMANY

Tel +49 (0) 3812081 - 0; Fax +49 (0) 3812081 - 202;

http://www.demogr.mpg.de

MPIDR WORKING PAPER WP 2015-012

DECEMBER 2015

\title{
Older parents enjoy better filial piety and care from daughters than sons in China
}

\author{
Zeng Yi (zengyi68@gmal.com) \\ Linda George \\ Melanie Sereny \\ Danan Gu \\ James W. Vaupel
}

(C) Copyright is held by the authors.

Working papers of the Max Planck Institute for Demographic Research receive only limited review. Views or opinions expressed in working papers are attributable to the authors and do not necessarily reflect those of the Institute. 


\section{Older parents enjoy better filial piety and care from daughters than sons in China}

--and policy discussions to reduce son-preference and high sex ratio at birth

\section{Zeng $\mathrm{Yi}^{1,2}$ *, Linda George ${ }^{1,3}$, Melanie Sereny ${ }^{4}$, Danan $\mathrm{Gu}^{5}$ and James W. Vaupel ${ }^{6}$}

${ }^{1}$ Center for the Study of Aging and Human Development, Medical School of Duke University.

${ }^{2}$ Center for Healthy Aging and Development Studies, National School of Development, Peking University.

${ }^{3}$ Department of Sociology, Duke University

${ }^{4}$ Department of Sociology \& Anthropology, University of Rhode Island

${ }^{5}$ Population Division, Department of Economic and Social Affairs, United Nations, NY.

${ }^{6}$ Max Planck Institute for Demographic Research

* Please address correspondence to: Yi Zeng, Center for the Study of Aging and Human Development at Medical School of Duke University, and Center for Healthy Aging and Development Studies, National School of Development, Peking University. Mailing address: Box 3003, Duke University, Durham, NC 27710, U.S.A. tel. 919-6607554; fax: 919-668-0453; Email: zengyi68@gmal.com.

Funding supports: This study is part of the project funded by NIA/NIH (R01AG023627-10), National Natural Science Foundation of China $(71110107025,71233001,71490732)$ and United Nations Funds for Population Activities.

\section{Abstract:}

This study based on analyzing the unique datasets of Chinese Longitudinal Healthy Longevity Survey clearly demonstrate that, compared to having son(s), having daughter(s) is beneficial at older ages, with regards to enjoying greater filial piety from and better relationships with children and satisfaction with care provided by children. The daughter-advantages of enjoying greater filial piety from and better relationships with children are more profound among oldest-old aged 80+ compared to young-old aged 65-79, and surprisingly more profound in rural areas compared to urban areas, while son-preference is much more prevalent among rural residents. We also discuss why the rigorous fertility policy until October 2015 and less-developed pension system in rural areas substantially contribute to the sustentation of the traditional sonpreference which resulted in high sex ratio at birth (SRB) when fertility is low. We recommend China to take integrative policy actions of informing the public that having daughter(s) is beneficial for old age care, developing rural pension system and implementing the most recently 
announced universal two-child policy as soon as possible. We believe that these policy actions would help China to change the traditional son-preference, bringing down the high SRB, and enable more future elderly parents to enjoy their life including better care provided by daughters.

\section{INTRODUCTION}

Sons were preferred to daughters in most societies for thousands of years (Arnold and Zhaoxiang 1986; Johansson and Nygren 1991; Yang and Wang 2003), and this pattern still persists in China, India and many other developing countries (Banister 2004; Echávarri and Ezcurra 2010; Seth 2010). The sentiment behind the old Chinese saying "Yang Er Fang Lao" -Having a son (rather than a daughter) prevents difficulties in old age-- is a belief held by many Chinese and is one of the main reasons for strong son-preference. However, after more than thirty years of dramatic economic growth and social reforms, including close exchanges with the Western world, does the traditional belief of "Having a son (rather than daughter) prevents difficulties in old ages" still match reality in contemporary China?

This article aims to address this research question and discuss the policy implications/recommendations using data from the Chinese Longitudinal Healthy Longevity Survey (CLHLS). In the following sub-sections of the introduction, we first briefly discuss the Chinese tradition of son-preference and the high sex ratio at birth (SRB) in recent decades. We also summarize existing literature on adult children's filial piety to and relationships with their older parents. The care provided by adult children to older parents in China and elsewhere also is summarized, with particular attention to comparisons between adult daughters and sons.

\subsection{Traditional son-preference and high SRB in the past three decades in China}

The son-preference in China is based on both cultural traditions and practical beliefs. According to Confucianism, only sons can perform ancestor worship and continue the family lineage (Ng, Phillips, and Lee 2002; Ebenstein and Leung 2010). Sons are more likely to co- 
reside with their elderly parents and provide financial support, especially in rural China. Chinese culture is traditionally patriarchal and daughters "marry out" and become members of their husband's extended family; thus, they are less likely to provide financial support to their natal parents than sons do (Bian, Logan and Bian 1998; Deutsch 2006). Rural household labor supply also favors sons as they are better farm laborers and can also enhance family power in local conflicts (Ebenstein and Leung 2010).

Until three decades ago it was only possible for those who have strong son-preference to influence the sex composition of their children by providing better nutrition and health care to boys than girls or, rarely, through infanticide of females. Thus, when fertility was high, every family could realize their preference to have a son by continuing to bear children until a son was born. Consequently, the sex ratio at birth (SRB) was normal even in societies where sonpreference prevailed, such as China before 1980. The SRB in China was rather close to the naturally normal level of 105 boys per 100 girls in the 1960s and 1970s. However, after the implementation of the rigid birth-control policy and fertility dramatically declined to close to -and eventually well below -- the replacement level ${ }^{1}$, son-preference could not be met because of limited births. The economic boom in China has made medical technology and facilities for prenatal sex determination widely available and affordable. Thus, people who have a strong preference for sons may easily bribe medical personnel to perform illegal prenatal sex identification and the couple can consequently abort female fetuses to achieve their desire of having a son (Banister 2004; Ebenstein 2010).

Consequently, the SRB in China climbed quickly after 1980, up to 110.9 in $1986,116.8$ in 2000, and 120.5 in 2005 (Bhattacharjya et al. 2008). In 2010, the SRB in China was 121.2 as reported in the latest census data. The SRB in rural areas in China tends to be significantly higher than that in urban areas (Banister 2004). The skewed SRB in China is likely due to a

\footnotetext{
${ }^{1}$ Replacement fertility refers to the level of fertility at which a cohort of women on average have only enough children to replace themselves and their partners in the population, and it is about 2.1 children per couple in China given the current mortality level.
} 
combination of factors - sex-selective abortion, under-reporting of female births, and a small amount of female infanticide (Guilmoto 2009; Zeng et al. 1993; Zhu, Lu and Hesketh 2009; Greenhalgh 2013). Loss of female births and infants due to son-preference will create an unbalanced population sex structure and result in serious social problems (Hull 1990; Tuljapurkar, Li and Feldman 1995; Park and Cho 1995; Greenhalgh, 2013).

The problem of rising SRB associated with traditional son-preference, a low fertility regime, and availability of new prenatal sex-determination technology/facilities has occurred not only in China, but also in many other developing countries where son-preference is high but fertility is quickly declining and the economy is growing. For example, in India, the SRB climbed from 104 in 1961 to 113 in the 2000s (Echávarri and Ezcurra 2010; Seth 2010) The SRB in some northern states of India persistently remains at over 115 (UNFPA 2011). The SRB in South Korea increased from 107 in the mid-twentieth century to 114 in the late 1980's, but decreased to 110 in the twenty-first century (Hesketh 2011). The SRB in some Caucasus countries such as Armenia and Azerbaijan climbed to more than 115 in recent years (United Nations Population Division, 2015).

In more developed countries in the late twentieth century, however, there is no sonpreference and no sex-selective abortion which biases SRB, although fertility is very low and the technology/facilities for prenatal sex-determination are widely available. In the United States, for example, some families prefer to have one child of each gender (Raley and Bianchi 2006). As explained by Nugent (2013), this "mixed gender" preference can be explained by different ideologies. The "separate spheres" ideology reflects the notion that the two genders have inherent differences, but each is valuable. In addition, having at least one son and at least one daughter stems from "rational choice" in meeting the needs of old-age care, such as financial support from sons, but hands-on caregiving (Schmid, Brandt, and Haberkern, 2012; Willyard et al. 2008) and emotional support (Leopold, Raab, and Engelhardt 2014) from daughters. This pattern reflects traditional gender roles. Caregiving falls under activities that are considered 
“women's work" - such as household chores and personal care (Miller and Cafasso 1992). For future generations, however, daughters may also be increasingly available to provide financial support as the gender pay-gap narrows and women have surpassed men in attending higher education. Some evidence suggests that gender indifference is increasing in some Confucian societies as well. Lin's research from Taiwan (2009) found a decline in son-preference over time and younger cohorts are more neutral in their child sex-preferences.

While son-preference is documented in a large number of developing countries, including China, a few societies demonstrate the opposite - daughter preference. This has been particularly noted for some matrifocal societies in the Caribbean countries (Fuse 2010; Quinlan 2006). For example, on the island nation of Dominica, female kin perform economic activities for the extended family, which leads to some families preferring and investing more in daughters than in sons (Quinlan 2006). Daughters are more reliable in providing both tangible assistance and emotional support to parents. In larger families, daughters may also be relied on for household tasks or care for younger children. Daughter preference has also been documented in several more developed societies, including the Czech Republic, Lithuania, and Portugal (Hank and Kohler 2000).

\subsection{Adult children's filial piety to and relationships with older parents}

The Confucian norm of filial piety has been a central pillar of cultural and moral ideals for Chinese and other Asian societies for thousands of years. Filial piety is a fundamental component of Confucianism; adult children are obligated to provide financial and/or emotional supports to their older parents (Ikels 2004; Johnson 1983). Adult children living with and providing care to elderly parents represents an embodiment of filial piety (Chappell and Kusch 2007; Mao and Chi 2011). Adult children who have stronger filial piety values are more likely to live with elderly parents (Zhang, Gu, and Luo 2014). Data from urban China found that adult children who agreed with patrilocal norms of filial piety were more likely to give financial 
assistance to their older parents than adult children who did not value filial piety (Zhan and Montgomery 2003; Zhan 2004). Adult children's filial piety includes emotional support to their older parents, in addition to instrumental and financial support. Several studies report a significant association between filial responsibility attitudes and emotional support to elderly parents. Research on Chinese-Canadians and Hong Kong-Chinese found agreement with filial piety to be associated with greater emotional support to older parents (Chappell and Funk 2012). A comparative study of 5 Western countries - Norway, England, Germany, Spain and Israel, found that close emotional relationships and a stronger sense of filial responsibility were associated with increased support for older parents (Lowenstein and Daatland 2006). In Japan, another society influenced by Confucianism, researchers found some evidence that older parents in families with more traditional attitudes towards filial piety received more emotional support from their children than did those with lower expectations for filial piety (Takagi and Saito 2013).

Questions remain as to whether Confucianism and norms of filial piety have been changed or weakened by the Communists taking over ruling power in Mainland China since 1949 and/or by more recent economic and social development. Although Confucianism was generally considered as being feudal under Chairman Mao's leadership (Chappell and Funk 2012; Chu, Xie, and Yu 2011), it was re-embraced as a virtue in the late 20th century and the basic ideas of filial piety persist or have even been promoted (Ikels 2004). In 1996, the central government passed a law protecting the rights of elders, which dictated adult children's obligations to respect and take care of their aged parents physically, financially, and emotionally. The law provided regulations for adult children's provision for aging parents in terms of housing and medical care, largely based on filial piety principles (Luo and Zhan 2012). The Chinese government promotes filial piety as a virtue and encourages adult children to care for their older parents, in large part because social welfare programs are underdeveloped especially in rural areas (Chappell and Kusch 2007). Filial piety, however, may have been weakened by the 
country's fundamental economic and social transformation, which resulted in a stronger focus on nuclear families and larger physical distances between elderly parents and adult children ( $\mathrm{Ng}$, Phillips, and Lee 2002). These changes may have affected adult sons more than adult daughters. In recent decades, free-choice marriages and increases in women's socioeconomic and familial status have led to stronger bonds between sons and their wives as a nuclear family unit. These trends could increase the conflict between daughters-in-law and mothers-in-law (as discussed below) and weaken adult sons' filial piety and relationships with their older parent. Compared to adult daughters, rural-to-urban and other job-related migration is more prevalent among adult sons, which increases their physical distance from and weaken filial piety contacts and relationships with their older parents.

In a review of the literature, Davis and Greenstein (2009) reported that men's beliefs about gender equality in taking care of older parents tend to lag behind those of women. Recent studies from rural China found that some elderly parents consider their daughters to be more filial than sons (Shi 2009; Luo and Zhan 2012), reflecting the Chinese saying: "A daughter is like a little quilted vest to warm her parents' hearts" (guinü shi bama de tiexin xiaomian'ao).

Thus, Chinese families may be shifting from filial piety as the primarily motivation for providing financial care for older parents to motivations mainly based on close emotional bonds (Laidlaw et al 2010). A study based on data from rural northern China reports that older parents are more satisfied with their relationships with adult daughters than with adult sons because of more conflict between older parents and sons/daughters-in-law. This study also found that daughters often help mediate the relationships between sons/daughters-in-law and older parents (Zhang and Wang 2010).

\subsection{Elderly parents' satisfaction with care from adult children}

Given that women handle the majority of housework in most Chinese families, caregiving from sons generally means that the actual hands-on care to aged parents in need is 
provided by sons' wives - daughters-in-law of elderly parents, while daughters usually marry out (Liu \& Kendig, 2000). In recent decades, daughters-in-law have more power within the family and husbands and wives more equally negotiate elderly care arrangements (Zhang \& Wang, 2010). These trends might increase disabled older parents' dissatisfaction with care from their sons (and daughters-in-law) due to conflicts between daughters-in-law and mothers-in-law. The latter are much more likely to occur and/or be serious than is true for daughter-mother relationships, especially in rural areas (Meng, 2002; Pearson, 2002; Zheng \& Lin, 1994). As men are less likely to be hands-on caregivers than women, there is much lower potential for conflict between older parents and sons-in-law in China and in Chinese enclaves in other societies (Chappell \& Kusch, 2007).

The Chinese tradition that sons provide more care to older parents than daughters do is in contrast with Western culture and social practices, which have been increasingly influencing Chinese society in recent decades. In Western countries, daughters are more likely than sons to provide daily care (Raley \& Bianchi, 2006; Spitze \& Logan, 1990), particularly personal care and household tasks (Abel, 1990; Miller \& Cafasso, 1992). Evidence from the US indicates that daughters also provide more emotional support than sons to both parents (Chesley \& Poppie, 2009). Research from the Netherlands found that daughters provide more emotional support to elderly mothers than do sons when the mothers experience a health decline (Broese Van Groenou \& Knipscheer, 1999). Studies have shown that daughters (both in other countries and urban China) are more likely to be actual caregivers than sons when older parents are sick (Spitze \& Logan, 1990; Whyte, 2003).

Survey data from urban China found that sons are more likely to provide financial support to their older parents and daughters are more likely to provide assistance in daily living and gifts to their older parents (Cooney \& Di, 1999; Sun, 2002; Zhan, 2004). In urban China, patrilocality may be declining, with the importance of sons (for old-age care) diminishing. Urban parents may be more willing to receive and be satisfied with support from daughters, but the 
perception of reliance on sons (and daughters-in-law), due to traditional son-preference, still persists in rural areas (Zhang \& Wang, 2010).

Research found that older adults received more emotional support from daughters than from sons in Hong Kong (Ng, Phillips, \& Lee, 2002) and in rural Mainland China (Cong \& Silverstein, 2012). This is consistent with the idea that daughters are kin-keepers of the family and more responsive to the needs of their older parents (Rossi \& Rossi, 1990; Li \& Seltzer, 2005). Several studies show that in urban China the proportion of elders who prefer and mainly rely on daughters for daily care exceeds the proportion of elderly who mainly rely on sons (and daughters-in-law). For example, data show that both daughters and sons provide financial assistance to old parents (Chen \& Adamchak, 1999) and married daughters provide amounts equivalent to (Whyte 2003) or even greater than sons (Xie \& Zhu, 2009). Yet many studies under-recognize the role of daughters in caring for impaired older parents, especially in rural China (Zhan, 2004).

\subsection{Hypotheses}

While filial piety, intergenerational relationships and transfers are often discussed in studies of aging in China as reviewed above, significant gaps in research on these issues remain. Specifically, no previous studies investigated differences between adult sons and daughters in filial piety norms and relationships with older parents, or compared disabled older parents' satisfaction with care received from their daughters and sons, based on a large, representative sample of older adults, contained detailed measures of adult children's attitudes and beliefs about filial piety. This study intends to address these research gaps by testing the two hypotheses:

$\mathrm{H} 1$ : Chinese elderly parents experience more filial piety from and better relationships with adult daughters than adult sons. 
$\mathrm{H}$ 2: Chinese disabled older parents whose primary caregiver is a daughter (and son-in-law) are more satisfied with the care they receive than those whose primary caregiver is a son (and daughter-in-law).

The oldest-old (aged 80+) are the most likely to need care and have been growing at a much faster rate than the young-old (aged 65-79) and rural-urban differences in social attitudes and old-age care systems are dramatically large in China (Zeng \& George, 2010). Yet, no previous studies of filial piety and intergenerational relationships have compared oldest-old and young-old parents or rural-urban differences. We also investigate these differences.

\section{DATA SOURCE, MEASURES AND METHODS}

\subsection{Data source}

We use two datasets from the Chinese Longitudinal Healthy Longevity Survey (CLHLS): (1) a sub-sample of 4,240 dyadic pairs of adult children and their elderly parents, interviewed in the CLHLS 2002 wave (see Table 1a) and (2) a pooled cross-sectional dataset of the fourth and fifth waves of the CLHLS, conducted in 2005 and 2008-2009, with a total sample size of 7,430

disabled respondents aged $65+$ (see Table $1 \mathrm{~b}$ ). The sampling frame for the CLHLS was a randomly selected half of the counties and cities in 22 of China's 31 provinces (Liaoning, Jilin, Heilongjiang, Hebei, Beijing, Tianjin, Shanxi, Shaanxi, Shanghai, Jiangsu, Zhejiang, Anhui, Fujian, Jiangxi, Shandong, Henan, Hubei, Hunan, Guangdong, Guangxi, Sichuan, and Chongqing $)^{1}$, which cover about $85 \%$ of the total population of China.

The CLHLS 2002 wave included a sub-sample of 4,240 elderly interviewees' adult children aged 35-65 (each sampled elderly participant was paired with one of his/her children) in eight provinces: Gaungdong, Jiangsu, Fujian, Zhejiang, Shandong, Shanghai, Liaoning, and Guangxi. If an elderly interviewee had only one eligible child (i.e., aged 35-65 and living in the sampling areas), that child was interviewed. If an elderly interviewee had two or more eligible adult 
children, either the elder or the younger child was interviewed, determined by whether the elderly interviewee was born in the first or the second 6 -months of the year $(6=12 / 2)$. If an elderly interviewee had three eligible adult children, either the eldest, the middle, or the youngest child was interviewed, determined by whether the elderly interviewee was born in the first, second or the third 4-months of the year $(4=12 / 3)$, and so forth.

The sub-sample of adult children adopted the sophisticated questionnaire of the Social Survey on Family Dynamics designed and carefully tested by a research team at Taiwan Academy Sinica in collaboration with investigators at the University of Michigan (Chu and Yu 2010). The CLHLS dyadic sub-sample has unique strengths: the mean age of old parents is $83.6(\mathrm{SD}=11.0)$ and the mean age of adult children is $50.3(\mathrm{SD}=8.6) .2,647$ dyadic pairs (58.2\% of the total paired samples) consist of oldest-old parent(s) aged 80+ with a child who is also elderly or nearly elderly. Similarly, the analyses of disabled older parents' satisfaction with daily care provided by their adult children include 7,019 oldest-old parents aged $80+$. To our knowledge, these are the largest sample sizes of the oldest-old examined in this research field.

Extensive data were collected in the CLHLS through face-to-face interviews using internationally standardized questionnaires adapted to the Chinese cultural and social context. Careful evaluations, including reliability coefficients, factor analysis, and studies of age reporting of the oldest-old participants indicate that the data quality of the CLHLS surveys is reasonably good (Goodkind, 2009; Gu \& Dupre, 2008; Zeng \& Gu, 2008).

--Tables $1 \mathrm{a}$ and $1 \mathrm{~b}$ about here---

\subsection{Measures of adult children's filial piety to and relationships with older parents}

The dataset used in this analysis includes information from the 4,240 dyadic pairs of adult children and their elderly parents, interviewed in the CLHLS 2002 wave.

\section{Dependent variables:}


(1) Filial piety to old parents. Adult children (aged 35-65) were asked to evaluate the following nine statements concerning filial piety to old parents: (1) Always being grateful to parents for their fosterage; (2) Respect for parents, no matter how parents treated you; (3) Give up your own aspirations to realize parent's expectations if the two are not the same; (4) Son should live with parents after he is married; (5) Support parents to enable them to have a better life; (6) Say some good words to save the face of parents; (7) Do something to enable your family to be honorable; (8) Daughter should frequently visit her own parents if she married out of her family; (9) Daughters have the same responsibility to support old parents as sons do. Response categories for the filial piety items were: 1 . Not important at all; 2. Not important; 3. So-so; 4. Important; 5. Very important. The Filial Piety Index was constructed by summing responses to the nine items (range $=9-45$ ). In analyses, the FPI was further coded into quartiles. The Cronbach's alpha of the Filial Piety Index scale is 0.75 , indicating acceptably good internal reliability (Nunnaly 1978).

Although items (4), (8), and (9) are explicitly about expected gender roles, we believe that they are appropriate for the filial piety index. Since the early 1980s, the Western preference for old parents and their adult children living independently has become more acceptable, especially among young urban residents. However, the traditional ideology of filial piety specifies that at least one son should live with his older parents after marriage and that daughters should frequently visit and provide support to their parents even after they "marry out" of their families. Some young people who subscribe to the Western culture of "independence between older parents and adult children" do not accept these traditional ideas. Even in traditional Chinese society, some people were "non-filial," as shown by the saying that "married-out daughters are like sloshed-out water," indicating that daughters do not share the same responsibility for supporting old parents as sons do. These traditional arguments are also used by some young people today to support their ideas against traditional filial piety. Because gender is an inherent part of Chinese filial piety, we believe that items (4), (8) and (9) are 
appropriate for the filial piety index. In addition, these nine items have been used in other studies measuring filial piety in surveys in Taiwan, Hong Kong, Singapore, Europe, and Israel (Lee, Netzer and Coward 1994; Laidlaw et al. 2010; Lowenstein and Daatland 2006; Wang et al. 2009; Yeh and Bedford 2004).

(2) Adult children's emotional relationships with their old parents. Adult children's emotional relationships with parents are measured by two questions: (a) How is your emotional relationship with your father? (b) How is your emotional relationship with your mother? The six responses available were: Very bad, Bad, So-so, Good, Very good, and Not applicable (i.e. father or mother died). We recoded this variable into three values, combining good and very good, combining very bad and bad, and leaving So-so as a separate category. Not applicable responses were coded as missing data and dropped from the analysis.

Key independent variable: gender of adult children ( $0=$ son, $1=$ daughter).

Potential confounding variables. We controlled for elderly parent's age, sex, urban/rural residence (defined by the respondents' actual long-term residential locations rather than the strict Chinese household registration (hukou) system), ethnicity (Han vs. non-Han), number of living children, education, economic status, marital status, proximity to children, health practices (including currently smoking, currently drinking alcohol and currently doing regular exercise) and health status (including ADL and cognitive function). We also controlled for adult children's age, urban/rural residence, education, economic status, marital status, number of children and self-rated health.

\subsection{Measures of disabled older parents' satisfaction with daily care provided by their adult children}


The dataset used in this analysis includes 7,430 disabled older parents who have at least one living child (see Table $1 \mathrm{~b}$ for age and rural/urban sample composition).

Dependent variable: disabled older parents' satisfaction with daily care received. An older parent was coded as disabled if he/she needed help to perform any of six activities of daily living (ADLs): bathing, dressing, indoor transferring, toileting, eating, and incontinence. Older disabled respondents were asked to identify their primary caregivers. A follow-up question asked: "Do you think the help that you receive with the above six tasks meets your needs?" Response categories were: "Fully met, So-so, or Not-met." We coded "fully met" as satisfaction with care and combined the last two categories to represent dissatisfaction with care.

Key independent variables: primary caregiver (son and daughter-in-law versus daughter and son-in-law). Identification of the primary caregiver is based on the question "Who is the primary caregiver when you need assistance in bathing, dressing, toileting, indoor transferring, continence, or eating?" The response categories were: spouse; son; daughter; daughter-in-law; son-in-law; grandchildren and their spouses; other relatives; friends/neighbors; social workers; housekeeper; nobody. Respondents were allowed to choose only one primary caregiver. Responses were coded by combining daughters and sons-in-law in one category and sons and daughters-in-law in another category to represent married units. Our analyses compare the odds ratios of daughters and sons-in-law versus sons and daughters-in-law.

Potential confounding variables: Older parents' age, sex, urban/rural residence, ethnicity, number of living children, education, economic status, marital status, and proximity to children were controlled in analysis. We did not control for the adult children's characteristics in our analysis on disabled older parents' satisfaction with daily care received, because data of detailed adult children's characteristics were only collected in the sub-sample of dyadic pairs of adult children and their elderly parents from the 8 provinces but we used the entire CLHLS sample from the 22 provinces here. 


\subsection{Statistical Methods}

Gender differentials (i.e.,daughters and sons-in-law vs. sons and daughters-in-law) in adult children's filial piety to old parents were analyzed using ordered logistic regression; binary logistic regression was used to examine gender differentials in adult children's emotional relationships with their older parents and disabled older parents' satisfaction with care. As in other studies (e.g. Crimmins, Hayward \& Saito, 1994), data from the disabled old parents in the 2005 and 2008-2009 waves were pooled to increase statistical precision and produce more robust results. We include only one observation for each disabled older parent in the analysis; thus, there are no intrapersonal cluster effects. Analyses controlling for survey wave did not substantively change the results and were dropped from further analysis. The proportion of missing data for all the variables in this study is less than $2 \%$; thus, we imputed missing values using the mode if the variables are categorical or binary and with means if they are continuous. Alternative strategies for imputing missing data were also tried and the results were almost identical.

\section{FINDINGS}

\subsection{Adult daughters' filial piety index is significantly higher than that of sons, especially} among the oldest-old and in rural areas

Estimates of the odds ratios of the filial piety index (FPI) of daughters versus sons are presented in panel (A) of Table 2. As compared to adult sons, adult daughters' FPI is significantly higher $(\mathrm{OR}=1.26 ; \mathrm{P}<0.01)$ for the rural-urban combined elderly parents aged $65+$, controlling for various confounding factors of both old parents and adult children. The oldest-old parents (aged $80+$ ) enjoyed significantly higher filial piety from their daughters $(O R=1.29$; $\mathrm{P}<0.05)$ than from their sons. The corresponding odds ratio estimate for young-old parents (aged 65-79) is 1.19 but not statistically significant. The daughters' higher FPI than sons' is 
stronger in rural areas $(\mathrm{OR}=1.37 ; \mathrm{P}<0.01)$ than in urban areas $(\mathrm{OR}=1.18$; not statistically significant).

--- Table 2 is about here-

\subsection{Adult daughters' emotional relationships with old parents are significantly better than those of sons}

The estimates presented in panels (B) and (C) of Table 2 show that adult daughters' emotional relationships with both older fathers and mothers aged 65+ (rural-urban combined) are significantly better than adult sons' $(P<0.01$; OR=1.28 or 1.30$)$, controlling for various confounding factors of old parents and adult children. The better emotional relationships between fathers and daughters (as compared to sons) is stronger among the old-old fathers than among the young-old fathers, but the opposite is true between oldest-old mothers and young-old mothers. Adult daughters' emotional relationships with older mothers aged 65+ are significantly better than adult sons' in rural areas $(\mathrm{OR}=1.29 ; \mathrm{P}<0.05)$, but is not significant in urban areas $(\mathrm{OR}=1.17)($ see panel $(\mathrm{C})$ of Table 2$)$.

\subsection{Disabled older parents are more satisfied with care provided primarily by daughters (and sons-in-law) than by sons (and daughters-in-law)}

Figure 1 presents the estimates of the odds ratios of satisfaction with care provided by a primary caregiver who is a daughter (and son-in-law) versus a son (and daughter-in-law) among all ADL disabled older parents regardless of number and sex composition of their living children. ADL disabled elderly aged 65+ (both genders combined) whose primary care-provider is a daughter (and son-in-law) are significantly more likely $(P<0.001$; OR $=1.41)$ to be satisfied with care received from children than their counterparts whose primary care-provider is a son (and daughter-in-law). The corresponding estimates are similar among oldest-old parents 80+ 
$(P<0.001 ;$ OR $=1.41)$, among younger parents aged 65-79 $(P<0.05 ;$ OR $=1.38) ;$ among urban elderly $(\mathrm{P}<0.001 ; \mathrm{OR}=1.50)$ and among rural elderly $(\mathrm{P}<0.05 ; \mathrm{OR}=1.29)$.

The odds ratios reflecting disabled older parents' higher satisfaction with care from a daughter (and son-in-law) than from a son (and daughter-in-law) are even more pronounced when only disabled older parents with both living sons and daughters are examined - see Figure 2. These findings demonstrate that daughters (and son-in-laws) provided more satisfactory care to their disabled older parents than sons (and daughter-in-laws) did, even when the family includes both sons and daughters.

---Figures 1 and 2 about here---

\section{DISCUSSION AND POLICY CONSIDERATIONS}

\subsection{Interpretations and implications of the empirical findings}

Our analysis clearly demonstrates that, as compared to having son(s), having daughter(s) is beneficial for Chinese older adults, with respect to enjoying better filial piety from and relationships with children, and more satisfaction with care provided by children, while controlling for various confounding factors. These patterns are even stronger among oldest-old parents than young-old parents, and in rural areas than urban areas, even though sonpreference is much more prevalent among rural residents. Our analysis has provided empirical evidence supporting the hypotheses based on the literature review and our prior research. These findings are fully consistent with those of a recent study (based on the CLHLS data) which reported that, as compared to having son(s), having daughter(s) is significantly more beneficial at older ages in China in terms of maintaining higher cognitive capacity and reducing mortality risk. In addition, daughter-advantages are stronger among the oldest-old than the young-old and in rural areas than in urban areas (Zeng et al. 2015). Thus, the findings of this and other studies suggest that the public perceptions that daughters are devalued and that sons provide better old-age care are, in fact, contradictory to the reality. This also means that 
aborting a female fetus to ensure having at least one son under low fertility is not a rational choice in the couple's own interests for better old age care in contemporary China.

What can explain these findings and implications, which are in opposition to the popular perception of son-preference, especially in rural areas of China? We believe that it may be at least partly explained by gender differentials in adult children's roles in supporting old parents and changes in these roles in recent years. First, although adult sons usually provide more financial support to their old parents in China, especially in rural areas, adult daughters are more likely to provide better personal and emotional care which are frequently needed at advanced ages, as shown in this and other studies (Spitze and Logan 1990; Sun 2002; Whyte 2003). The elderly who have no sons or whose son migrated elsewhere for job reasons are very likely to live with or close-by a married daughter. They then have no choice but to rely on help from daughter(s) and they may be better off, as studies have shown that daughters (both in China and other countries) prove to be better caregivers. Xie and Zhu (2009) found that the daughters who co-reside with parents in rural areas (going against traditional living arrangements) may have an unobserved characteristic, such as emotional closeness with parents, which enables the older parents to enjoy better filial piety and care from and closer relationships with their daughters. In contrast, the elderly who have son(s) only may be relatively better-off in terms of financial support, but their daily and emotional care may be of lower quality than that received by elderly who have daughter(s) only (see Table 2 and Figure 1).

Second, conflicts in daily life between daughters-in-law and mothers-in-law may play an important role. Our study shows that disabled elderly are more likely to be satisfied with care they receive from a daughter and her husband (son-in-law) rather than from a son and his wife (daughter-in-law). A study of older Chinese adults living in Canada also found that daughters-inlaw reported less positive interactions with their older in-laws than daughters reported with their elderly parents (Chappell and Kusch 2007). Other previous research indicates that conflicts between daughters-in-law and their mothers-in-law are more common and more serious than 
conflicts beween daughters and their mothers, especially in rural areas (Meng 2002; Pearson 2002; Zheng and Lin 1994). Additionally, the strengthening of the nuclear family (as opposed to the extended family) and free-choice marriage in recent years may lead to stronger bonds between sons and their wives and increases in conflicts between daughter-in-laws and mothersin-laws (Gallin 1994). As men are less likely to be caregivers than women, there is lower potential for conflict between old parents and their sons-in-law. Furthermore, the more complicated household work in rural areas may result in more frequent direct interactions and higher likelihood of conflict about daily tasks between daughters-in-law and mothers-in-law than in urban areas. The generally lower education levels of rural daughters-in-law and mothers-inlaw may also result in their poorer capability of resolving daily life conflicts as compared to their urban counterparts. The conflicts between daughters-in-law and mothers-in-law may be more likely to occur in rural areas today than in the past because sons are often absent due to ruralto-urban labor migration, which has increased dramatically in recent years.

Third, after more than thirty years of rapid economic and social development, compared to sons, rural daughters can acquire more education, technical skills and economic capacity, which may reduce their disadvantages and increase their status in familial affairs and power, and reduce the gap between daughters and sons (Xu 2001). Therefore, although peasants' predominant perception of son-preference persists, the traditional advantages of sons may be relatively weaker today.

\subsection{Two other important factors operating to contribute to son-preference and high SRB in China}

In spite of empirical evidence of and theoretical explanations for better caregiving from daughters than sons to old parents in China today, why do many Chinese people (especially those in rural areas) still prefer sons and abort female fetuses to guarantee having a son under the low fertility regime? Furthermore, to reverse the dangerous trend of rising SRB, the Chinese 
government launched a large-scale, nationwide campaign named "Caring for and Loving Girls Actions (CLGA)" in 2003. The campaign focused on helping "only-daughter families" and "twodaughters families" to provide better education, health care and employment assistance to the girls. Tremendous efforts and funds were devoted to the campaign to diminish son-preference and girl-disadvantage, to promote equality between men and women, and to reduce SRB.

Despite this campaign, however, the SRB in China increased by nearly 4 percentage points (up to 120.5 ) between 2000 and 2005 and increased slightly again to 121.2 in 2010 . We believe that two policy-related major problems are operating to sustain the son-preference and interfer with the CLGA program.

The first major problem has been the Chinese fertility policy up to October 2015, which contributed to the fact that China's SRB is one of the highest in the world. Implementation of the initial strict one-child policy in the early 1980s met strong resistance from peasants. Thus, in 1984, the government replaced it with a "1.5-child policy" instead in most rural areas. Specifically, if the first child was a girl, the couple were allowed to have a second child; otherwise, only one child was allowed. Members of minority nationalities also were generally allowed to have two or more births per couple. Guo and colleagues (2003) estimated that the 1child, 1.5-child, 2-child, and 3-child policies affected 35.9, 52.9, 9.6, and 1.6 percent of China's population, respectively, and remained quite stable until recently. The estimated SRBs in 2000 after adjusting for the underreporting of female births in the 1-child, 1.5-child, 2-child, and 3-child policy areas, were $110.0,120.0,108.1$, and 107.4, respectively (Guo, 2005). It is a shock that the excess of SRB (compared to the normal SBR of 105) in the 1.5-child policy areas was 4.9 times as high as that in the two-child policy areas, based on the 2000 census data. Why? We believe that the unexpected side-effects of the 1.5-child policy have played an important role. The 1.5-child policy implicitly tells peasants that one boy is sufficient for family welfare, including old age care, but one girl is not and another child is needed. This implies that the value of a male birth is trice as high as that of a female birth. Such implicit psychological effects may 
sustain or even strengthen the traditional son-preference which leads peasants whose first child is a girl to conduct prenatal sex determination and sex-selective abortion in order for the second birth to be male. Based on empirical data and simple algebra, Zeng (2007) estimated that about 19.1 percent of couples whose first child was a girl aborted their female fetus in a second pregnancy in 1.5-child policy areas, in contrast to 4.6 percent in two-child policy areas.

A great deal of evidence indicates that the SRB of second births of couples whose first child is a boy, is normal. But these couples are not allowed to have a second birth under the 1.5-child policy. This, in fact, eliminates about half of the second births of normal SRB, and thus causes structural effects towards a higher SRB. Simple algebra and numerical simulations have shown that even assuming the same rate of abortion of female fetuses under both the 1.5-child and two-child policy, the structural effects would lead to the SRB under the 1.5-child policy to be more than one-third higher than that under the two-child policy (Zeng, 2007).

The second major problem is the lack of pensions in rural China, where elderly rely heavily on monetary transfers and other kinds of economic support, mainly from sons. In contrast, the elderly in urban areas in China and developed countries get most of their support from pensions and personal savings. Based on the 2008-2009 CLHLS data, rural elderly receive 91 percent $(p<0.001)$ more financial support (cash and materials) ${ }^{2}$ from sons than daughters and urban elderly receive 31 percent $(p<0.001)$ more from sons than daughters. The financial support is particularly crucial for rural elderly who did not have any retirement pension income until very recently. This financial support may lead peasants to maintain their strong sonpreference.

In the early 1990s, an experimental program of basic pensions subsidized by local communities and governments in rural areas in China was first launched in Shandong province, and the experiment quickly spread to the rest of the country. By the end of 1999, there were about 80 million peasant participants of the basic pension program, accounting for 17.9 percent of the total number of rural residents aged $20+$; and about 890,000 peasants aged $60+$ started 
to receive very limited monthly payments from the program, which accounted for 1.1 percent of the total population of elderly in rural areas. Unfortunately, however, the program stagnated after 1999 because policy-makers did not consider it a top priority. By the end of 2004, there were about 53.9 million participants, about one third lower than in 1999. Lack of pensions in rural China is one of the major reasons why, despite large investment, the government's CLGA campaign with large input did not reverse the trend of a rising SRB.

The most recent development in rural old age insurance programs was that in September 2009, the Chinese State Council officially announced the development of the nationwide "New Rural Pension Program (NRPP)" (Ye, 2009). Since then, the NRPP has developed rapidly. According to $\mathrm{Hu}$, Yang and Yan (2015), the number of participants in NRPP reached 460 million by the end of 2012, which represents nearly full coverage in rural China. The NRPP has much more government funding than the previous old age insurance program. In the new program, the premium is jointly paid by individuals and the government and the government ensure a minimum income for all elderly who participate in the program. NRPP's effectiveness, however, remains to be seen and more effort is needed to increase its efficiency and especially to effectively implement the pension program in poorer rural areas. Successful implementation of the NRPP program would contribute positively and effectively to reduce son-preference and the high SRB.

\subsection{Policy recommendations}

As a result of the evidence, interpretations and implications discussed above, we recommend following three integrative policy-relevant actions for China.

(1) Effectively inform the public about daughter-advantages in caring for disabled older parents.

As outlined earlier, the CLGA program, implemented since 2003, focused on helping onlydaughter families and two-daughters families to provide better education, health care and employment assistance to the girls. This program is one meaningful method of correcting the 
devaluation of daughters. It is possible, however, that the CLGA promotes the false impression that girls are "weak" and need extra resources that boys do not, thereby reinforcing the traditional son-preference which caused high SRB. This image can be countered by publicizing the ways in which daughters provide better care to their older parents than sons do, as evidently shown by present study. Moreover, it is not fair to that the facts of daughter-advantages are still covered up or diluted by the strong traditional son-preference. Thus, we propose to add publicizing the factual daughter-advantages into the CLGA and other propaganda programs (such as media reports, movies, and TVs shows) aimed at reducing and finally eliminating the son-preference and high SRB. We suggest the Chinese policy makers and medias to effectively inform the public that daughters' better emotional care to old parents is beneficial to older parents' well-being, including enjoying greater filial piety from and better relationships with children, higher satisfaction with care received when need, and also maintaining higher cognitive capacity and reducing mortality risk (Zeng et al. 2015), especially in rural areas and at oldest-old ages, demonstrated by the empirical data analysis based on the large national longitudinal surveys.

(2) Further develop pension systems in both rural and urban areas.

We propose that the Chinese government further develop pension systems for all citizens in both rural and urban areas, as a national strategic action. This is extremely important in two ways. First, it is a necessary response to the challenges of rapid aging which will be even more serious in rural areas in the coming decades, due to the continuing rural to urban migration of young people (Zeng and Wang 2014), Second, adequate pensions will help to reduce and eventually eliminate the traditional son-preference and high SRB. Current programs available in rural areas do not provide adequate financial support and, thus, sustain the traditional son-preference and the dangerous trend of a rising sex ratio at birth. As long as farmers must rely on sons for old age care, they will continue to choose prenatal sex 
determination and abort female fetus to ensure having son(s). An excessive SRB would eventually cause societal instability.

(3) Implementing the most-recently-announced universal two-child policy as soon as possible.

Discussions in section 4.2 of this article and many other studies indicate that China's rigorous fertility policy (until most recently contributed substantially to sustaining the traditional son-preference and high SRB (e.g. Zeng, 2007; Zeng, 2015). In October 2015, the Central Committee of the Chinese Communist Party announced a universal two-child policy to replace the previous rigorous fertility policy, and the new policy has not yet been implemented as it needs to be evaluated and approved by the People's Congress which will meet soon. We propose that China needs to implement the universal two-child policy in rural and urban areas as soon as possible in order to reduce and eventually eliminate son-preference and high SRB which cause dangerous social problems of biased gender structure, in addition to avoid many other serious socioeconomic problems including too much aging and labour shortage in the future (Zeng and Wang, 2014).

We believe that implementing the universal two-child policy as soon as possible will not cause new baby booms and will help China to reduce its high SRB, based on the empirical evidences confirmed by numerous studies using data from national and regional surveys. Various studies have shown that, for most areas of contemporary China, the preferred number of children per couple is two, or one in substantial proportion of couples, or none among notignorable portion of young people in cities (Zhao and Chen, 2011). Even in the less developed Western and rural areas of China, the proportion of peasants who prefer three or more children is not high at all (Zheng 2004). Overall, China is now truly a low-fertility society (e.g., Feng and Zhang 2002; Cai 2010; Zhao and Guo 2010; Zhao and Chen 2011).

Our trust is also based on a comparison of fertility level and the SRB statistics between four rural experimental areas (Yi Chen county in Shanxi province, Jiu Quan prefecture in Ganshu province, Cheng De prefecture in Hebei province and En Shi prefecture in Hubei 
province, with a total population size 8.4 million) in which two-child plus promoting appropriate spacing policies have been implemented since the middle 1980s for more than 30 years, while the 1.5-child policy has been implemented in their surrounding rural areas. These two-child policy experimental areas and their surrounding areas are all rural regions with similar socioeconomic development levels and traditional son-preference culture. The universal twochild experimental rural areas, however, all have a total fertility rate less than 2.0 , which are slightly lower or almost the same as that in their surrounding rural areas in which the 1.5-child policy has been implemented. The SRBs in the two-child policy experimental rural areas are rather close to a normal value and substantially lower than the SRB in the surrounding rural areas (Gu et al. 2008).

\section{CONCLUDING REMARKS}

Based on the findings presented in this and other studies, we conclude that the publicly predominant son-preference which depreciates the value of daughters and assumes that sons will provide better support and care to older parents, especially in rural areas, is incorrect, because it is based on traditional beliefs and does not represent today's reality in China. Those who abort a female fetus in order to insure having at least one son in the context of low fertility do not make a rational choice with respect to their own interests for better old age care. Until October 2015, China's fertility policy significantly contributed to rural people's sustained sonpreference and very high SRB. The recent change in fertility policy is critically important and long overdue, but it will take time for it to undermine son preference. Furthermore, a large majority of older parents in rural areas in China rely on sons for financial support and the NRPP is not yet very mature and well-developed. This also supports people's sustained sonpreference and encourages abortion of female fetuses in order to have at least one son. Thus, we recommend that China take three actions as soon as possible: (1) effectively informing the public about daughters' advantages in caring for disabled older parents; (2) further developing 
the pension system to fully cover all rural and urban areas, as a national strategic action; (3) promoting rapid implementation of the new universal two-child policy. These three actions would help to ameliorate the most pressing social problems in China, such as changing the traditional son-preference, promoting equality between men and women, bringing down the high SRB to avoid serious social instability caused by a "marriage squeeze", and enabling more future elderly parents to enjoy their lives, including better care provided by daughters.

\section{REFERENCES}

Abel, E.K. 1990. "Informal care for the disabled elderly." Research on Aging 12(2):139.

Arnold, F.and L. Zhaoxiang. 1986. "Sex Preference, Fertility, and Family Planning in China." Population and Development Review 12(2):221-246.

Banister, J. 2004. "Shortage of girls in China today." Journal of Population Research 21(1):1945.

Bhattacharjya, D., A. Sudarshan, S. Tuljapurkar, R. Shachter, and M. Feldman. 2008. "How can economic schemes curtail the increasing sex ratio at birth in China?" Demographic research 19(54):1831.

Bian, F., J.R. Logan, and Y. Bian. 1998. "Intergenerational relations in urban China: Proximity, contact, and help to parents." Demography 35(1):115-124.

Buber, I.and H. Engelhardt. 2008. "Children's impact on the mental health of their older mothers and fathers: findings from the Survey of Health, Ageing and Retirement in Europe." European Journal of Ageing 5(1):31-45.

Byers, A.L., B.R. Levy, H.G. Allore, M.L. Bruce, and S.V. Kasl. 2008. "When Parents Matter to Their Adult Children: Filial Reliance Associated With Parents' Depressive Symptoms." The Journals of Gerontology Series B: Psychological Sciences and Social Sciences 63(1):P33-P40.

Chahnazarian, A. 1988. "Determinants of the sex ratio at birth: Review of recent literature." Biodemography and Social Biology 35(3):214-235.

Chappell, Neena L. and Laura Funk. 2012. "Filial Responsibility: Does it Matter for Care-Giving Behaviours?" Ageing and Society 32(07):1128-1146.

Chappell, N.L.and K. Kusch. 2007. "The gendered nature of filial piety-a study among Chinese Canadians." Journal of Cross-Cultural Gerontology 22(1):29-45. 
Chen, S.and D.J. Adamchak. 1999. "The effects of filial responsibility expectations on intergenerational exchanges in urban China." Hallym International Journal of Aging 1(2):58-68.

Chu, CY C. and Ruoh-Rong Yu. 2010. Understanding Chinese Families: A Comparative Study of Taiwan and Southeast China. New York: Oxford University Press.

Crimmins, E.M., M.D. Hayward, and Y. Saito. 1994. "Changing Mortality and Morbidity Rates and the Health Status and Life Expectancy of the Older Population." Demography 31(1):159175.

Deutsch, F.M. 2006. "Filial piety, patrilineality, and China's One-child policy." Journal of Family Issues 27(3):366.

Ebenstein, A. 2010. "The" Missing Girls" of China and the Unintended Consequences of the One Child Policy." Journal of Human Resources 45(1):87.

Ebenstein, A.and S. Leung. 2010. "Son Preference and Access to Social Insurance: Evidence from China's Rural Pension Program." Population and Development Review 36(1):47-70.

Echávarri, R.A.and R. Ezcurra. 2010. "Education and gender bias in the sex ratio at birth: Evidence from India." Demography 47(1):249-268.

Folstein, M.F., S.E. Folstein, and P.R. McHugh. 1975. "'" Mini-mental state". A practical method for grading the cognitive state of patients for the clinician." Journal of Psychiatric Research 12(3):189-198.

Fuse, Kana. 2010. "Variations in Attitudinal Gender Preferences for Children Across 50 LessDeveloped Countries." Demographic Research 23(36):1031-1048.

Gallin, R.S. 1994. "The intersection of class and age: Mother-in-law/daughter-in-law relations in rural Taiwan." Journal of Cross-Cultural Gerontology 9(2):127-140.

Goodkind, D. 2009. " [Review of the book Healthy Longevity in China: Demographic, Socioeconomic, and Psychological Dimensions]." Population Studies 63(3):1-7.

Gu, D.and M.E. Dupre. 2008. "Assessment of reliability of mortality and morbidity in the 19982002 CLHLS waves." Pp. 99-116 in Healthy Longevity in China: Demographic, Socioeconomic, and Psychological Dimensions, edited by Y. Zeng, D. Poston, D.A. Vlosky, and D. Gu. Dordrecht: Springer.

Guilmoto, C.Z. 2009. "The Sex Ratio Transition in Asia." Population and Development Review 35(3):519-549.

Guo, Z. 2005. "An analysis on fertility by regions implementing different policies in China based on the 2000 census data." in Reports of the Research Projects on 2000.

Guo, Z., E. Zhang, B. Gu, and F. Wang. 2003. "Diversity of China's fertility policy by policy fertility." Population Research 27(5):1-10.

Hank, Karsten and Hans-Peter Kohler. 2000. "Gender Preferences for Children in Europe: Empirical Results from 17 FFS Countries." Demographic Research 2(1):133-144. 
Hesketh, T. 2011. "Selecting sex: The effect of preferring sons." Early human development 87(11):759-761.

Hu, A., Yang, Z., \& Yan, Y. (2015). Trends and tasks of social security in China in the 13th fiiveyear national development plan period. Journal of the Party School of the Central Committee of the C.P.C, 1, 85-90. [in Chinese].

Hull, T.H. 1990. "Recent trends in sex ratios at birth in China." Population and Development Review 16(1):63-83.

Johansson, S.and O. Nygren. 1991. "The Missing Girls of China: A New Demographic Account." Population and Development Review 17(1):35-51.

Johnson, K. A. 1983. Women, the Family and Peasant Revolution in China.Chicago: The University of Chicago Press.

Leopold, Thomas, Marcel Raab and Henriette Engelhardt. 2014. "The Transition to Parent Care: Costs, Commitments, and Caregiver Selection among Children." Journal of Marriage and Family 76(2):300-318.

Li, L., J. Liang, A. Toler, and S. Gu. 2005. "Widowhood and depressive symptoms among older Chinese: Do gender and source of support make a difference?" Social Science \&amp; Medicine 60(3):637-647.

Lin, Tin-chi. 2009. "The Decline of Son Preference and Rise of Gender Indifference in Taiwan since 1990." Demographic Research 20:377.

Lowenstein, Ariela and Svein O. Daatland. 2006. "Filial Norms and Family Support in a Comparative Cross-National Context: Evidence from the OASIS Study." Ageing and Society 26(2):203-224.

Luo, Baozhen and Heying Zhan. 2012. "Filial Piety and Functional Support: Understanding Intergenerational Solidarity among Families with Migrated Children in Rural China." Ageing International 37(1):69-92.

Meng, L. 2002. "Rebellion and revenge: the meaning of suicide of women in rural China." International Journal of Social Welfare 11(4):300-309.

Miller, B.and L. Cafasso. 1992. "Gender differences in caregiving: fact or artifact?" The Gerontologist 32(4):498.

National Population and Family Planning Commission of P.R. China. 2011. Beijing, China http://www.chinapop.gov.cn/

Ng, Anita C. Y., David R. Phillips and William K. Lee. 2002. "Persistence and Challenges to Filial Piety and Informal Support of Older Persons in a Modern Chinese Society: A Case Study in Tuen Mun, Hong Kong." Journal of Aging Studies 16(2):135-153.

Nugent, Colleen N. 2013. "Wanting Mixed-Sex Children: Separate Spheres, Rational Choice, and Symbolic Capital Motivations." Journal of Marriage and Family 75(4):886-902. 
Park, C.B.and N.H. Cho. 1995. "Consequences of son preference in a low-fertility society: imbalance of the sex ratio at birth in Korea." Population and Development Review 21(1):59-84.

Pearson, V. 2002. "Ling's death: An ethnography of a Chinese woman's suicide." Suicide and Life-Threatening Behavior 32(4):347-358.

Pham-Kanter, G.and N. Goldman. 2011. "Do sons reduce parental mortality?" Journal of Epidemiology and Community Health.

Pollard, M.S.and S.P. Morgan. 2002. "Emerging parental gender indifference? Sex composition of children and the third birth." American Sociological Review 67(4):600.

Quinlan, Robert J. 2006. "Gender and Risk in a Matrifocal Caribbean Community: A View from Behavioral Ecology." American Anthropologist:464-479.

Raley, S.and S. Bianchi. 2006. "Sons, daughters, and family processes: Does gender of children matter?" Annu. Rev. Sociol. 32:401-421.

Schmid, Tina, Martina Brandt and Klaus Haberkern. 2012. "Gendered Support to Older Parents: Do Welfare States Matter?" European Journal of Ageing 9(1):39-50.

Seth, S. 2010. "Skewed sex ratio at birth in India." Journal of biosocial science 42(01):83-97.

Shi, Lihong. 2009. "'Little Quilted Vests to Warm Parents' Hearts": Redefining the Gendered Practice of Filial Piety in Rural North-Eastern China." The China Quarterly 198:348-363.

Silverstein, M.and V.L. Bengtson. 1991. "Do close parent-child relations reduce the mortality risk of older parents?" Journal of Health and Social Behavior:382-395.

Spitze, G.and J. Logan. 1990. "Sons, daughters, and intergenerational social support." Journal of Marriage and Family 52(2):420-430.

Sun, R. 2002. "Old age support in contemporary urban China from both parents' and children's perspectives." Research on Aging 24(3):337-359.

Takagi, Emiko and Yasuhiko Saito. 2013. "A Longitudinal Analysis of the Impact of Family Support on the Morale of Older Parents in Japan: Does the Parent's Normative Belief in Filial

Responsibilities make a Difference?" Ageing and Society 33(06):1053-1076.

Tuljapurkar, S., N. Li, and M.W. Feldman. 1995. "High sex ratios in China's future." Science 267(5199):874.

UNFPA. 2011. "Trends in sex ratio at birth and estimates of girls missing at birth in India (20012008). UNFPA-India, New Delhi.

Whyte, M.K. 2003. "China's Revolutions and Intergenerational Relations." Ann Arbor: The University of Michigan Press.

Willyard, J., K. Miller, M. Shoemaker and P. Addison. 2008. "Making Sense of Sibling Responsibility for Family Caregiving." Qualitative Health Research 18(12):1673-1686. 
Xie, Y.and H. Zhu. 2009. "Do sons or daughters give more money to parents in urban China?" Journal of Marriage and Family 71(1):174-186.

Xu, Y. 2001. "Family support for old people in rural China." Social Policy \& Administration 35(3):307-320.

Yang, C.and Y. Wang. 2003. Theses Collection of 2001 National Family Planning and Reproductive Health Survey (in Chinese). Beijing, China: China Population Publishing House.

Ye, Z. 2009. "Establish a green cover for people - the 60-years of the social security program in China." in People's Daily (overseas edition). Beijing.

Zeng, Y. 2007. "Options for fertility policy transition in China." Population and Development Review 33(2):215-246.

Zeng, Y.and D. Gu. 2008. " Reliability of Age Reporting among the Chinese Oldest-old in the CLHLS Datasets." Pp. 39-58 in Healthy Longevity in China: Demographic, Socioeconomic, and Psychological Dimensions, edited by Y. Zeng, D. Poston, D.A. Vlosky, and D. Gu. Dordrecht: Springer.

Zeng, Y., T. Ping, G. Baochang, X. Yi, L. Bohua, and L. Yongpiing. 1993. "Causes and implications of the recent increase in the reported sex ratio at birth in China." Population and Development Review:283-302.

Zeng, Y. and Wang Z. 2014. A Policy Analysis on Challenges and Opportunities of Population/Household Aging in China. Journal of Population Aging, 7 (4): 255-28; DOI 10.1007/s12062-014-9102-y.

Zeng Y., Brasher, M., Gu, D. and Vaupel, J. W. 2016, Older Parents Benefit More in Health Outcome From Daughters' Than Sons' Emotional Care in China. Forthcoming in Journal of Aging and Health.

Zeng, Yi, 2015. Implementing the universal two-child policy as soon as possible is a win-win policy for both the nation and people. Population and Ecomics, No. 5, 2015.

Zhao, Z. and Chen, W. (2011) China's far below-replacement fertility and its long-term impact: Comments on the preliminary results of the 2010 census, Demographic Research, Vol. 25 (26): 819-836.

Zhang, G. and Zhao Z. 2006. Reexamining China's Fertility Puzzle: Data Collection and Quality over the Last Two Decades. Population and Development Review, 32(2): 293-321.

Zhang, Z. 2006. "Gender differentials in cognitive impairment and decline of the oldest old in China." The Journals of Gerontology Series B: Psychological Sciences and Social Sciences 61(2):S107-S115.

Zhang, Z., Gu, D., \& Luo, Y. (2014). Coresidence with elderly parents in contemporary China: The role of filial piety, reciprocity, socioeconomic resources, and parental Needs. Journal of Cross-Cultural Gerontology, 29(3), 259-276. 
Zheng, Y.P.and K.M. Lin. 1994. "A nationwide study of stressful life events in Mainland China." Psychosomatic medicine 56(4):296-305.

Zhu, W.X., L. Lu, and T. Hesketh. 2009. "China's excess males, sex selective abortion, and one child policy: analysis of data from 2005 national intercensus survey." BMJ 338(apr09_2):b1211b1211.

Zunzunegui, M.V., F. Beland, and A. Otero. 2001. "Support from children, living arrangements, self-rated health and depressive symptoms of older people in Spain." International Journal of Epidemiology 30(5):1090.

\footnotetext{
${ }^{1}$ A wide variety of international and Chinese studies (Coale \& Li, 1991; Wang et al., 1998; Poston \& Luo, 2004) had confirmed that age reporting of Han Chinese oldest-old is acceptably accurate, but age reporting of the minority ethnic groups in China who have not adopted Chinese cultural tradition is not accurate. The acceptably accurate age reporting of Han Chinese is due to their cultural tradition of memorizing their date of birth for determining important life events such as dates of engagement, marriage, starting to build a residential house, and even for long-distance traveling. To ensure accurate age reporting among the sampled oldest-old interviewees, the CLHLS selected 22 provinces where Han Chinese are majority as study areas and the other 9 provinces were excluded, because the minority ethnics groups whose age report is not accurate are majority there.
}

2. The old parents self-reported financial supports of cash and materials received from adult children did not include daily expenses (e.g. food, clothes, medical costs etc.) paid by the coresiding children. Because the Chinese elderly are more likely live with a married son than with a married daughter, the excess of financial support received from sons as compared to that from daughters was underestimated. 
Figure 1: Odds ratios of satisfaction with care from daughters (and sons-in-law) as primary caregiver versus sons (and daughters-in-law) as primary caregivers, among all disabled older parents who have at least one living child, based on data from 2005 and 2008-2009 waves of CLHLS

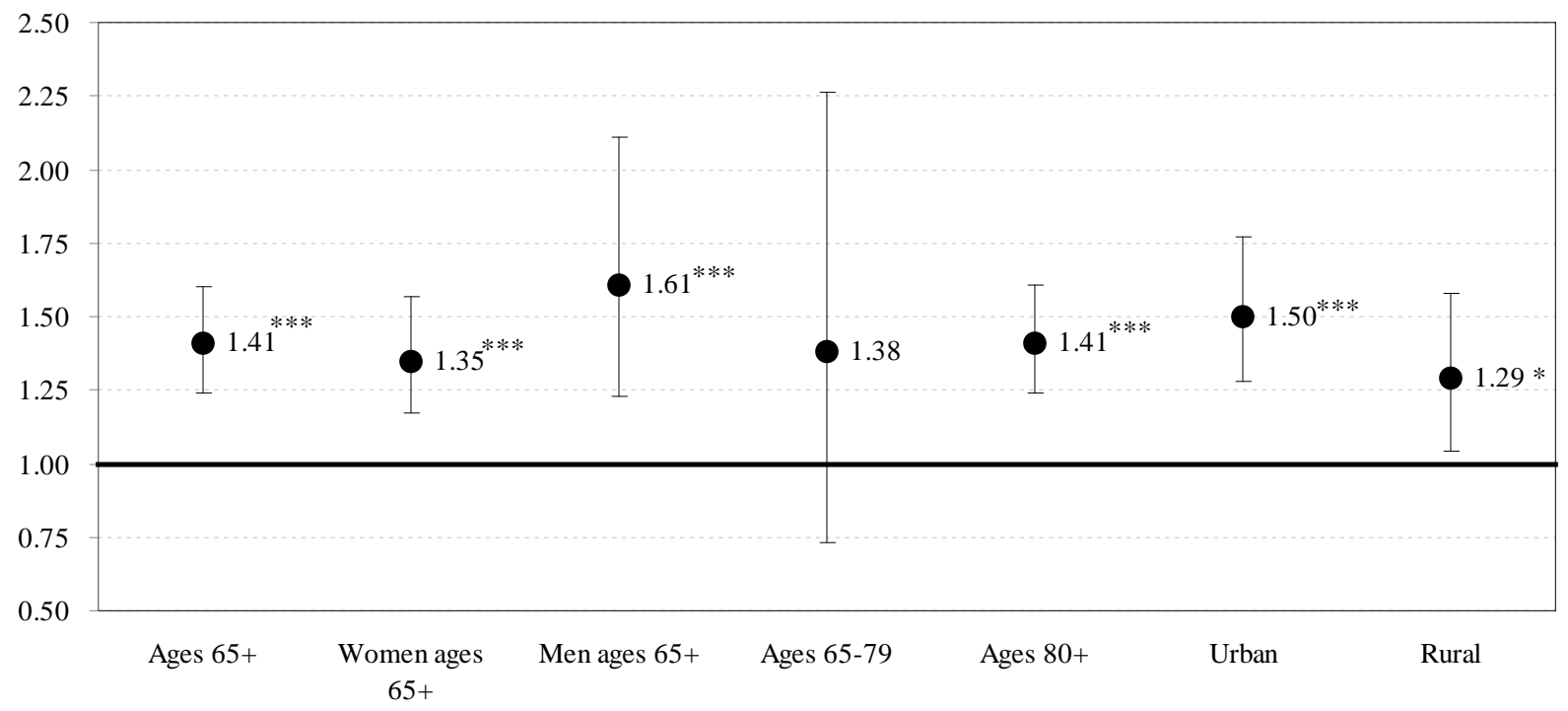

Note: (1) The total sample size for the old parents aged $65+$ in the analysis presented in this Figure was 7,430. (2) +,p<0.1; ${ }^{\star}, p<0.05 ;{ }^{* *}, p<0.01 ;{ }^{\star \star \star}, p<0.001$. (3) The chi-square test results indicated that the model fits of the statistical models presented in this figure are significant.

Figure 2: Odds ratios of satisfaction with care from daughters (and sons-in-law) as primary caregivers versus sons (and daughters-in-law) as primary caregivers, among disabled older parents who have both son(s) and daughter(s), based on data from 2005 and 2008-2009 waves of CLHLS

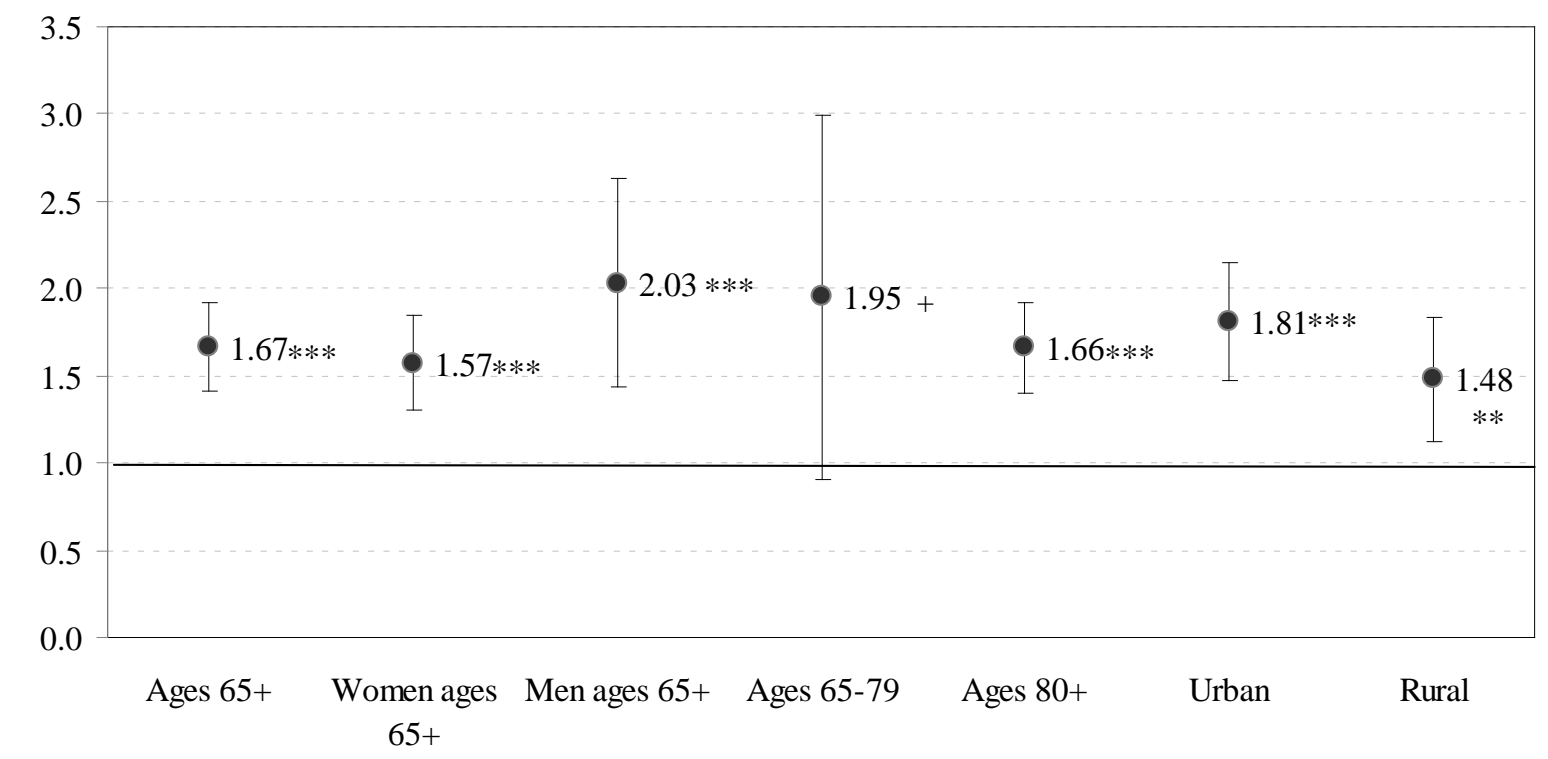

Note: (1) The total sample size for the old parents aged $65+$ in the analysis presented in this Figure was 4,891. (2),$+ p<0.1 ;{ }^{*}, p<0.05$; ${ }^{\star *}, p<0.01 ;{ }^{* \star *}, p<0.001$. (3) The chi-square test results indicated that the model fits of the statistical models presented in this figure are significant. 
Table 1a. Descriptive Statistics of dyadic pairs of adult child and his/her elderly parents, interviewed in the CLHLS 2002 wave

\begin{tabular}{|c|c|c|c|c|c|}
\hline \multirow{3}{*}{$\begin{array}{l}\text { Characteristics of adult sons or adult } \\
\text { daughters and the elderly parents }\end{array}$} & \multicolumn{5}{|c|}{$\begin{array}{l}\text { Age range of elderly parents and the rural-urban } \\
\text { residence }\end{array}$} \\
\hline & \multicolumn{3}{|c|}{ Rural and urban combined } & \multicolumn{2}{|c|}{ Ages 65+ } \\
\hline & Ages 65+ & Ages 65-79 & Ages 80+ & Urban & Rural \\
\hline \multicolumn{6}{|l|}{ Adult sons } \\
\hline Sample size & 3,020 & 1,115 & 1,905 & 1,321 & 1,693 \\
\hline Average filial piety score & 37.9 & 37.8 & 37.9 & 37.9 & 37.9 \\
\hline $\begin{array}{l}\text { \% good emotional relation with } \\
\text { mother }\end{array}$ & 29.5 & 33.5 & 27.2 & 32.5 & 27.2 \\
\hline$\%$ good emotional relation with father & 34.6 & 36.6 & 33.4 & 38.8 & 31.1 \\
\hline Mean ages & 50.6 & 43.6 & 54.6 & 50.5 & 50.6 \\
\hline$\%$ rural & 62.3 & 61.2 & 37.1 & 74.3 & 90.9 \\
\hline Average years of schooling & 7.4 & 8.4 & 6.8 & 8.3 & 6.7 \\
\hline $\begin{array}{l}\% \text { self-rated high socioeconomic } \\
\text { status }\end{array}$ & 46.4 & 48.9 & 44.9 & 46.3 & 46.5 \\
\hline Average number of children & 2.2 & 1.6 & 2.5 & 1.8 & 2.4 \\
\hline Average household size & 4.4 & 4.1 & 4.5 & 4.2 & 4.5 \\
\hline$\%$ currently married & 92.6 & 93.3 & 92.2 & 91.6 & 93.4 \\
\hline $\begin{array}{l}\% \text { good self-rated health } \\
\text { Adult daughters }\end{array}$ & 81.1 & 87.1 & 77.8 & 80.9 & 81.6 \\
\hline Sample size & 1,307 & 565 & 742 & 704 & 601 \\
\hline Average filial piety score & 38.0 & 38.0 & 38.1 & 38.1 & 38.0 \\
\hline $\begin{array}{l}\text { \% good emotional relation with } \\
\text { mother }\end{array}$ & 37.1 & 39.6 & 35.2 & 42.6 & 30.8 \\
\hline$\%$ good emotional relation with father & 43.8 & 45.7 & 42.3 & 48.9 & 37.8 \\
\hline Mean ages & 49.6 & 43.6 & 52.3 & 49.6 & 49.7 \\
\hline$\%$ rural & 50.6 & 50.4 & 50.7 & 81.4 & 14.3 \\
\hline Average years of schooling & 6.8 & 7.8 & 6.1 & 8.5 & 5.0 \\
\hline $\begin{array}{l}\% \text { self-rated high socioeconomic } \\
\text { status }\end{array}$ & 46.6 & 49.7 & 44.2 & 51.0 & 41.4 \\
\hline Average number of children & 2.1 & 1.7 & 2.4 & 1.7 & 2.5 \\
\hline Average household size & 3.9 & 3.8 & 4.0 & 3.6 & 4.2 \\
\hline$\%$ currently married & 89.5 & 94.5 & 85.7 & 89.2 & 89.9 \\
\hline \multicolumn{6}{|l|}{$\begin{array}{l}\text { Older parents } \\
\text { Older }\end{array}$} \\
\hline Sample size & 4,327 & 1,680 & 2,647 & 2,025 & 2,302 \\
\hline Mean ages & 83.3 & 72.1 & 90.5 & 83.1 & 83.5 \\
\hline$\%$ with $1+$ years of schooling & 43.3 & 48.3 & 37.2 & 50.8 & 36.7 \\
\hline$\%$ with economic independence & 29.9 & 46.6 & 18.5 & 43.4 & 17.9 \\
\hline Mean \# of living children & 3.7 & 4.2 & 3.4 & 3.6 & 3.8 \\
\hline$\%$ close proximity with children & 51.4 & 55.2 & 49.0 & 39.0 & 62.3 \\
\hline \% Currently smokes & 18.5 & 24.0 & 15.1 & 16.6 & $20 / 2$ \\
\hline$\%$ Currently drinks alcohol & 20.1 & 23.1 & 18.2 & 18.9 & 21.2 \\
\hline$\%$ currently doing regular exercise & 32.5 & 38.9 & 28.4 & 43.0 & 23.3 \\
\hline$\%$ ADL disabled & 22.9 & 6.8 & 33.2 & 24.8 & 21.3 \\
\hline$\%$ cognitive impaired & 30.5 & 7.5 & 45.1 & 26.0 & 34.5 \\
\hline
\end{tabular}


Table 1b. Descriptive statistics of the disabled older parents interviewed in 2005 and 2008-2009 waves of the CLHLS

\begin{tabular}{lccccc}
\hline & \multicolumn{3}{c}{ Rural and urban combined } & \multicolumn{2}{c}{ Ages 65+ } \\
\hline & Ages 65+ & Ages 65-79 & Ages 80+ & Urban & Rural \\
\hline Sample size of disabled elderly & $n=7,430$ & $n=411$ & $n=7,019$ & $n=3,705$ & $n=3,725$ \\
Composition of living children (\%) & & & & & \\
$\quad$ No living children & 10.3 & 3.8 & 12.9 & 11.9 & 9.2 \\
Having 1+ daughter(s) only & 11.8 & 5.8 & 14.1 & $12 . .8$ & 11.0 \\
Having 1+ son(s) only & 14.6 & 12.3 & 15.4 & 14.0 & 15.0 \\
$\quad$ Having both son(s) and daughter(s) & 63.3 & 78.1 & 57.6 & 61.3 & 64.8 \\
\% Satisfied among those with daughter & 50.1 & 50.0 & 50.1 & 53.3 & 44.1 \\
$\quad$ (and son-in-law) as primary caregiver & & & & & \\
\% Satisfied among those with son (and & 39.4 & 39.3 & 39.4 & 42.0 & 37.1 \\
daughter-in-law) as primary caregiver & & & & & \\
Control variables & & & & & \\
Mean Age & 86.6 & 72.0 & 92.7 & 86.5 & 86.5 \\
\% Han Ethnicity & 93.8 & 94.1 & 93.7 & 95.6 & 92.5 \\
\% currently married & 28.3 & 62.2 & 15.1 & 29.9 & 27.1 \\
\% Having 1+ years of schooling & 27.2 & 37.9 & 23.1 & 30.0 & 25.1 \\
\% with economic independence & 19.2 & 32.5 & 14.1 & 35.8 & 6.8 \\
Mean number of living children & 3.2 & 4.0 & 2.9 & 3.1 & 3.4 \\
\% Close proximity to children & 66.5 & 75.9 & 62.9 & 51.4 & 77.9 \\
\% Currently smokes & 18.5 & 28.4 & 14.6 & 16.7 & 19.8 \\
\% Currently drinks alcohol & 20.6 & 24.6 & 19.1 & 19.0 & 21.9 \\
\% Currently does regular exercise & 29.7 & 39.2 & 25.9 & 39.4 & 22.4 \\
\hline
\end{tabular}

Table 2. Odds ratios of adult children's filial piety index and emotional relations with elderly parents: daughters versus sons, based on the CLHLS adult children and old parents survey in 2002

\begin{tabular}{lcccccc}
\hline Age range of elderly parents & \multicolumn{3}{c}{ Rural and urban combined } & \multicolumn{2}{c}{ Ages 65+ } \\
\cline { 2 - 7 } and the rural-urban residence & Ages 65+ & Ages 65-79 & Ages 80+ & Urban & Rural \\
\hline $\begin{array}{l}\text { (A) Adult children's filial piety } \\
\text { index (daughters versus sons) }\end{array}$ & $1.18^{\star}$ & 1.13 & $1.20^{\star}$ & 1.16 & $1.23^{\star}$ \\
& & $1.04-1.35)$ & $(0.92-1.40)$ & $(1.01-1.43)$ & $(0.96-1.40)$ & $(1.02-1.49)$ \\
$\begin{array}{l}\text { (B) Good emotional relation } \\
\text { with father (daughters versus }\end{array}$ & $1.43^{\star \star \star}$ & $1.23-1.67)$ & $(1.06-1.71)$ & $(1.14-1.86)$ & $(1.24-1.90)$ & $(0.99-1.56)$ \\
sons) & & & & & \\
$\begin{array}{l}\text { (C) Good emotional relation } \\
\text { with mother (daughters versus } \\
\text { sons) }\end{array}$ & $1.45^{\star \star \star}$ & $1.25-1.68)$ & $(1.21-1.93)$ & $(1.18-1.74)$ & $(1.14-1.72)$ & $(1.19-1.84)$ \\
\hline
\end{tabular}

Notes: (1) Results for the filial piety index are based on ordered logistic regressions, while the results for the relationship with old parents are based on binary logistic regressions.

(2) All odds ratios estimates are adjusted for the confounding variables of the elder parents and adult children listed in Table 1a. The confounding variables for the elderly parents include age, sex, urban/rural residence, ethnicity, number of living children, years of schooling, economic independence, marital status, proximity to children, health practice, and health conditions, whereas confounding variables for adult children include age, years of schooling, self-rated overall socioeconomic status, marital status, number of living children, household size, and self-rated health. Estimates of the odds ratios for controlled covariates are not listed here due to space limit, but available upon request.

(3) $+p<0.1 ;{ }^{*}, p<0.05 ;{ }^{* \star}, p<0.01 ;{ }^{* \star \star}, p<0.001$. 